\title{
BMJ Open Factors associated with receiving surgical treatment for menorrhagia in England and Wales: findings from a cohort study of the National Heavy Menstrual Bleeding Audit
}

Rebecca Sally Geary, ${ }^{1,2}$ Ipek Gurol-Urganci, ${ }^{1,2}$ Amit Kiran, ${ }^{1,2}$ David A Cromwell, ${ }^{1,2}$ Loveleen Bansi-Matharu, ${ }^{3}$ Judy Shakespeare, ${ }^{4}$ Tahir Mahmood, ${ }^{2}$ Jan van der Meulen ${ }^{1,2}$

To cite: Geary RS, GurolUrganci I, Kiran A, et al. Factors associated with receiving surgical treatment for menorrhagia in England and Wales: findings from a cohort study of the National Heavy Menstrual Bleeding Audit. BMJ Open 2019;9:e024260. doi:10.1136/ bmjopen-2018-024260

- Prepublication history and additional material for this paper are available online. To view these files, please visit the journal online ( $h$ ttp://dx.doi. org/10.1136/bmjopen-2018024260).

Received 17 May 2018 Revised 23 November 2018 Accepted 23 November 2018

Check for updates

(C) Author(s) (or their employer(s)) 2019. Re-use permitted under CC BY-NC. No commercial re-use. See rights and permissions. Published by BMJ.

For numbered affiliations see end of article.

Correspondence to Dr Rebecca Sally Geary; rebecca.geary@Ishtm.ac.uk

\section{ABSTRACT}

Objective To examine the factors associated with receiving surgery for heavy menstrual bleeding (HMB) in England and Wales.

Design National cohort study.

Setting National Health Service hospitals.

Participants Women with HMB aged 18-60 who had a new referral to secondary care.

Methods Patient-reported data linked to administrative hospital data. Risk ratios (RR) estimated using multivariable Poisson regression.

Primary outcome measure Surgery within 1 year of first outpatient clinic visit.

Results 14545 women were included. At their first clinic visit, mean age was 42 years, mean symptom severity score was 62 (scale ranging from 0 (least) to 100 (most severe)), $73.9 \%$ of women reported having symptoms for $>1$ year and $30.4 \%$ reported no prior treatment in primary care. One year later, $42.6 \%$ had received surgery. Of these, $57.8 \%$ had endometrial ablation and $37.2 \%$ hysterectomy. Women with more severe symptoms were more likely to have received surgery (most vs least severe quintile, $33.1 \%$ vs $56.0 \%$; RR $1.6,95 \% \mathrm{Cl} 1.5$ to 1.7 ). Surgery was more likely among those who reported prior primary care treatment compared with those who did not (48.0\% vs $31.1 \%$; RR $1.5,95 \% \mathrm{Cl} 1.4$ to 1.6). Surgery was less likely among Asian and more likely among black women, compared with white women. Surgery was not associated with socioeconomic deprivation.

Conclusions Receipt of surgery for HMB depends on symptom severity and prior treatment in primary care. Referral pathways should be locally audited to ensure women with HMB receive care that addresses their individual needs and preferences, especially for those who do not receive treatment in primary care.

\section{INTRODUCTION}

Heavy menstrual bleeding (HMB) affects one in four women of reproductive age. It is a condition that impairs the quality of life of many women who are otherwise healthy. ${ }^{1}$

\section{Strengths and limitations of this study}

- This study uses national audit data from England and Wales to examine initial treatments for heavy menstrual bleeding immediately after referral to secondary care.

- The sample is relatively large allowing comparisons between minority ethnic groups.

- Linking audit data with administrative hospital data also allowed comparisons between socioeconomic groups.

- The recruitment rate of $30 \%$ was not as high as desired, but the characteristics of those recruited were broadly representative of the UK population in terms of ethnicity and age.

- The collection of patient-reported symptom severity addresses a knowledge gap about how women feel about their heavy menstrual bleeding and the treatment they receive.

Every year in England and Wales, an estimated 50000 women with HMB are referred to secondary care provided by the National Health Service (NHS). ${ }^{2}$ This constitutes approximately $20 \%$ of referrals to specialist gynaecology services, ${ }^{3}$ and approximately 28000 women undergo surgical treatment. ${ }^{4}$ In the majority of women, the cause of their HMB is not known. ${ }^{5}$

Medical treatments for HMB include (oral) medication and the levonorgestrel -releasing intrauterine system(LNG-IUS). Surgical treatment, including endometrial ablation (EA) and hysterectomy, is an option if medical treatment is ineffective or undesirable. ${ }^{156} \mathrm{~A}$ systematic review of randomised clinical trials suggest that EA, hysterectomy and LNG-IUS all reduce $\mathrm{HMB}$ and are more acceptable to most women than oral medication. ${ }^{1}$ The 
review found that surgical treatment is most effective over the short term although the quality of included trials was limited. ${ }^{1}$ Hysterectomy will stop HMB but around $3 \%$ of women experience potentially serious postoperative complications. ${ }^{7}$ EA and LNG-IUS appear to be safe, acceptable and effective treatments for HMB although some women who have EA will require a repeat procedure. $^{18-10}$

Since the early 1990s, there has been a steady increase in the use of EA rather than hysterectomy in women who have surgical treatment for HMB. ${ }^{11}$ Since 2004, more EA procedures than hysterectomies have been conducted in England. ${ }^{41-13}$ Previous studies have found regional variations in rates of surgery for HMB in England large enough to suggest scope for improvements in HMB management. ${ }^{3} 121415$ In addition, women from socioeconomically deprived areas report more severe HMB at their first outpatient gynaecology visit ${ }^{16}$ and higher rates of hysterectomy for HMB, than women living in the least deprived areas, ${ }^{8}$ potentially reflecting inequitable access to secondary care and use of surgery for HMB.

In this paper, we investigate the factors that determine whether women who have been referred to secondary care for HMB get surgical treatment. We use patient-reported data from the National HMB Audit linked to administrative hospital databases: Hospital Episode Statistics (HES) and the Patient Episode Database for Wales (PEDW). We explore the impact that symptom severity, treatment received in primary care and patient characteristics including age, ethnicity and socioeconomic deprivation have on the chance that women receive surgical treatment in the first year after their referral to secondary care.

\section{METHODS \\ Data}

Women aged between 18 and 60 years in England and Wales who had a new referral for HMB to a gynaecology outpatient clinic of an NHS hospital were eligible to participate in the National HMB Audit. ${ }^{2} 41317$ The National HMB Audit took place between 2010 and 2014, with an estimated recruitment rate of $32 \% .^{2}{ }^{17}$ National HMB Audit data were linked at the patient level (by a trusted third party) to HES and PEDW, administrative databases containing records of all admissions to NHS hospitals in England and Wales to provide data on treatments received in secondary care.

\section{Measures}

Women were considered to have had a surgical procedure for HMB (the study outcome) if any HES/PEDW procedure field described abdominal or vaginal hysterectomy, EA, myomectomy or uterine artery embolisation (UAE), recorded using UK Office for Population Censuses and Surveys classification, fourth revision codes. ${ }^{18}$ For women who underwent a surgical procedure for HMB, information on underlying conditions was available from HES/
PEDW, recorded using International Classification of Diseases, 10th Revision codes. ${ }^{19}$ These were grouped as: 'endometriosis (with or without uterine fibroids or polyps)', 'uterine fibroids and/or polyps (no endometriosis)' and 'no obvious cause'. Women without codes for uterine fibroids, polyps or endometriosis, but with code(s) indicating excessive or irregular menstrual bleeding, were classed as having no obvious cause of their HMB. The codes used to define surgery and underlying conditions are detailed in the online supplementary appendix S1.

Women who gave informed consent completed a baseline questionnaire (in the gynaecology outpatient clinic of an NHS hospital before their consultation) on age (categorised as 18-34, 35-39, 40-44, 45-49, 50-60), ethnicity (grouped as 'white', 'Asian or Asian British', 'black or black British' and 'other' (combining 'Chinese', 'mixed' and 'other'), duration and severity of HMB symptoms, obstetric history (analysed as 'nulliparous' or 'parous'), prior HMB treatment and comorbidities. To capture comorbidities (grouped: 0,1 and 2 or more) women were asked 'Have you been told by a doctor that you have any of the following?' with the response options: heart disease, high blood pressure, lung disease, diabetes, depression, thyroid disorder, kidney disease and cancer (in the last 5 years). Body mass index (BMI, grouped: $<25$, 25-30 and $\geq 30$ ) was derived from self-reported height and weight. ${ }^{20}$ The Index of Multiple Deprivation (IMD), an area-level measure of relative socioeconomic deprivation, was extracted from HES/PEDW and analysed as quintiles $(1=$ most deprived areas, $5=$ least deprived areas $)$ according to the national distribution. Further information is given in the online supplementary appendix S2.

Women were asked: 'How long have you had symptoms of HMB?' ('2 months or less', ' $>2$ months but $<1$ year', '>1 year' or 'don't know'), analysed as ' $<1$ year', ' $\geq 1$ year'. Symptom severity scores were derived from the Uterine Fibroid Symptom and Quality of Life (UFS-QOL) questionnaire adapted for the HMB Audit. ${ }^{21}$ Scores could range from 0 (least severe, best possible score) to 100 (most severe, worst possible score), analysed in quintiles. Further information is provided in the online supplementary appendix S3.

\section{Statistical analysis}

We present descriptive statistics (means and proportions) of patient and HMB-related characteristics and treatment received in the year after the first outpatient clinic visit for HMB. For descriptive statistics, those who had more than one surgical treatment in the year following their first outpatient clinic visit were categorised by the last likely surgical treatment (according to clinical experience and protocol).

We used multivariable Poisson regression with robust SEs to estimate risk ratios (RR) that represent the associations between patient and HMB-related characteristics reported by women at their first gynaecology outpatient clinic visit and receiving surgical treatment in the first 
year following this. ${ }^{22}$ We chose to report risk ratios (RRs) rather than ORs because the latter are more difficult to interpret, especially if the proportions being compared are relatively large. In a secondary analysis, we examined the associations between these characteristics and whether women received EA or hysterectomy among those having one of these procedures. Women who received both EA and a hysterectomy in the year following their first outpatient visit $(n=699)$ were included in the EA treatment group for this analysis because EA was the first procedure. We tested for interaction between both ethnicity and BMI and HMB-related condition.

Levels of missing data were low $(<3 \%)$ for the majority of variables but $7 \%$ of women were missing ethnicity data and $23 \%$ were missing height or weight data required to derive BMI (table 1). For regression analyses missing values were imputed using multiple imputation by chained equations ${ }^{23}$ with statistical coefficients obtained using 10 imputed data sets, pooled using Rubin's rules. ${ }^{24}$ Analyses were performed in Stata V.15.

\section{Patient involvement}

The National HMB Audit was supported by a clinical reference group which included lay members and patient representatives. The lay members and patient representatives provided input to the design of the study and interpretation of the results, and contributed to the dissemination plan. The clinical reference group met on a regular basis for the duration of the audit. Women with HMB also participated in a pilot study to assess the logistical issues of the prospective National HMB Audit. This informed the design of written materials and key procedures for the audit. Ninety-six women with HMB also participated in interviews to refine and psychometrically evaluate the adapted UFS-QOL instrument.

\section{RESULTS}

\section{Description of the cohort}

A total of 15325 eligible women completed the questionnaire at their first visit to a gynaecology outpatient clinic. Up to 14545 women $(94.9 \%)$ could be linked to HES or PEDW for information on surgical treatments and deprivation. Of these women, 11.6\% $\quad(n=1578)$ reported minority ethnic backgrounds (black, $\mathrm{n}=571$; Asian, $n=731$ ), with the distribution of ethnicities broadly representative of the UK population. ${ }^{25}$ The mean age of women was 42.4 years (SD: 7.6) and the mean BMI was $27.3 \mathrm{~kg} / \mathrm{m}^{2}$ (SD: 5.4) (table 1). The majority of women had given birth $(83.1 \%, \mathrm{n}=11727)$ and one-third reported comorbidities $(33.8 \%, \mathrm{n}=4925)$. The mean score for symptom severity at first outpatient clinic visit was 61.8 (SD: 21.3) and this score ranged from 34.3 (SD: 10.8) in the least severe symptoms quintile to 93.8 (SD: 5.1) in the most severe symptoms quintile. Almost three-quarters of women reported HMB symptoms for more than 1 year and nearly a third $(30.4 \%)$ reported that they had not
Table 1 Characteristics of women at their initial HMB outpatient visit

\begin{tabular}{|c|c|}
\hline Denominator $(n=14545)$ & $\begin{array}{l}\%(n) \text { unless } \\
\text { otherwise } \\
\text { stated }\end{array}$ \\
\hline Age (years), mean (SD) & $42.4(7.6)$ \\
\hline \multicolumn{2}{|l|}{ Age group (years) } \\
\hline $18-34$ & $14.8(2155)$ \\
\hline $35-39$ & $12.9(1881)$ \\
\hline $40-44$ & $26.6(3870)$ \\
\hline $45-49$ & $31.3(4554)$ \\
\hline $50-60$ & $14.3(2085)$ \\
\hline \multicolumn{2}{|l|}{ Ethnicity } \\
\hline White & $88.4(11987)$ \\
\hline Asian or Asian British & $4.2(731)$ \\
\hline Black or black British & $5.4(571)$ \\
\hline Other & $2.0(276)$ \\
\hline Missing & $6.7(980)$ \\
\hline \multicolumn{2}{|l|}{ Socioeconomic deprivation (IMD*) } \\
\hline Quintile 1 (most deprived) & $23.5(3418)$ \\
\hline Quintile 2 & $21.7(3159)$ \\
\hline Quintile 3 & $20.2(2944)$ \\
\hline Quintile 4 & $18.7(2720)$ \\
\hline Quintile 5 (least deprived) & $15.8(2304)$ \\
\hline BMI, mean (SD) & $27.3(5.4)$ \\
\hline \multicolumn{2}{|l|}{ BMI categories } \\
\hline$<25$ & $39.5(4424)$ \\
\hline $25-30$ & $31.7(3569)$ \\
\hline$\geq 30$ & $28.8(3226)$ \\
\hline Missing & 23.0 (3346) \\
\hline \multicolumn{2}{|l|}{ Parity } \\
\hline Nulliparous & $16.9(2378)$ \\
\hline Parous & $83.1(11727)$ \\
\hline Missing & $3.0(440)$ \\
\hline \multicolumn{2}{|l|}{ Number of comorbidities } \\
\hline 0 & $66.1(9620)$ \\
\hline 1 & $25.4(3701)$ \\
\hline$\geq 2$ & $8.4(1224)$ \\
\hline \multicolumn{2}{|l|}{ Overall health } \\
\hline Excellent/very good & $37.4(5356)$ \\
\hline Good & $42.0(6009)$ \\
\hline Fair/poor & 20.7 (2958) \\
\hline Missing & $1.5(222)$ \\
\hline \multicolumn{2}{|l|}{ Symptom severity at baseline } \\
\hline $\begin{array}{l}\text { Severity score at baseline (overall), mean } \\
\text { (SD) }\end{array}$ & $61.8(21.3)$ \\
\hline \multicolumn{2}{|l|}{$\begin{array}{l}\text { Severity score at baseline (quintiles), } \\
\text { mean (SD) }\end{array}$} \\
\hline & Continued \\
\hline
\end{tabular}




\begin{tabular}{cc}
\hline Table 1 Continued & \\
\hline Denominator (n=14545) & $\begin{array}{l}\% \text { (n) unless } \\
\text { otherwise } \\
\text { stated }\end{array}$ \\
\hline Quintile 1 (least severe) & $34.3(10.8)$ \\
Quintile 2 & $56.5(4.4)$ \\
Quintile 3 & $68.5(2.6)$ \\
Quintile 4 & $78.9(3.4)$ \\
Quintile 5 (most severe) & $93.8(5.1)$ \\
Duration of symptoms & $26.1(3677)$ \\
$<1$ year & $73.9(10434)$ \\
$\geq 1$ year & $3.0(434)$ \\
Missing & \\
Prior treatment for HMB in primary care & $30.4(4296)$ \\
No & $69.6(9819)$ \\
Yes & $3.0(430)$ \\
Missing &
\end{tabular}

*Index of Multiple Deprivation, an area-level measure of relative socioeconomic deprivation.

BMI, body mass index; HMB, heavy menstrual bleeding.

received medical treatment for their HMB in primary care before referral (table 1).

\section{Treatment received in the year following first outpatient clinic visit}

Approximately $40 \%$ of women received surgical treatment for HMB in the year following their first outpatient clinic visit $(42.6 \%$, table 2$)$, with most of those undergoing EA (57.8\%) or hysterectomy (37.2\%). The small number of women receiving UAE $(n=129)$ or myomectomy $(\mathrm{n}=179)$ precluded further analysis of these groups separately.

\section{Receipt of surgical treatment by women's characteristics}

Symptom severity at first outpatient clinic visit and medical treatment received for HMB in primary care were associated with surgical treatment received in the year following first outpatient clinic visit. The rate of surgical treatment was higher among those reporting the most severe symptoms than among those reporting the least severe symptoms (RR comparing the most to the least severe symptoms quintile $1.5,95 \%$ CI 1.4 to 1.6 , table 2). Receipt of surgery was highest among those aged 40-44 and 45-49 years, where half $(49.9 \%)$ had received surgery, and lowest among women aged 18-34 years (18.4\%, table 2$)$, despite similar mean symptom severity scores for the 18-34year-olds (63.3, SD: 20.8) and the 40-45 and 45-49year-olds (62.7, SD: 21.2 and 61.6, SD: 21.2, data not shown).

The rate of surgery was higher among women who reported prior treatment in primary care than among those who did not (RR 1.4, 95\% CI 1.4 to 1.5 , table 2 ), and among those who reported a longer duration of symptoms at their initial outpatient visit for HMB (RR 1.3, $95 \%$ CI 1.2 to 1.4). Among women who reported that they had received prior treatment in primary care, the proportion that had received surgery was highest among those reporting the most severe symptoms in all age groups, and use of surgery increased with age up to ages 40-49 years (figure 1). Among those who reported that they had not received prior treatment in primary care these patterns were broadly similar, although the relationship between symptom severity and surgery was less marked for women aged 35-39 years where a similar proportion of women in each of the three most severe symptom quintiles received surgery (figure 1). The proportion of women who received surgery was markedly lower among women aged between 18-34 years and who reported the least severe symptoms, than for women aged $45-49$ years and who reported the most severe symptoms, among both those who had, and those who had not, received treatment in primary care. Among the women who reported having had prior treatment in primary care, the proportion receiving surgery among 18-34year-olds with symptoms in the least severe quintile was $14 \%$ compared with $70 \%$ of $45-49$ year-olds with symptoms in the most severe quintile. Corresponding percentages among those who reported no prior treatment in primary care were $11 \%$ and $48 \%$, respectively (figure 1). Adjusting for patient characteristics had only a small impact on the magnitude of the associations observed between both symptom severity and prior treatment in primary care and the rate of surgery.

Other characteristics were associated with the receipt of surgery although the magnitude of the associations was smaller than for symptom severity or prior treatment. Higher rates of surgical treatment were seen in women who had given birth, and those who had a higher BMI (25-30 or $\geq 30)$. Compared with white women, women reporting an Asian background had lower rates of surgery (RR $0.8,95 \%$ CI 0.7 to 0.9 ), while women of black ethnic backgrounds had higher rates (RR 1.1, 95\% CI 1.0 to 1.2, table 2). Socioeconomic deprivation was not associated with surgical treatment.

\section{Type of first surgical treatment received by women's characteristics}

Symptom severity was associated with having hysterectomy rather than EA (table 3). Among women who underwent EA or a hysterectomy, the rate of hysterectomy was higher among those reporting the most severe symptoms compared with those reporting the least severe symptoms (RR comparing most vs least severe symptoms quintile $1.6,95 \%$ CI 1.3 to 1.8$)$. Women who reported a longer duration of symptoms at their initial outpatient visit for HMB were more likely to have undergone a hysterectomy than EA (RR 1.2, 95\% CI 1.1 to 1.4). Those who were obese (BMI 25-30) had higher rates of hysterectomy than those of a healthy weight (BMI <25) (RR 1.2, 95\% CI 1.1 to 1.3). Adjusting for patient characteristics had only a small impact on the magnitude of the associations 
Table 2 Characteristics associated with receiving surgical treatment in the first year following an initial outpatient visit for HMB

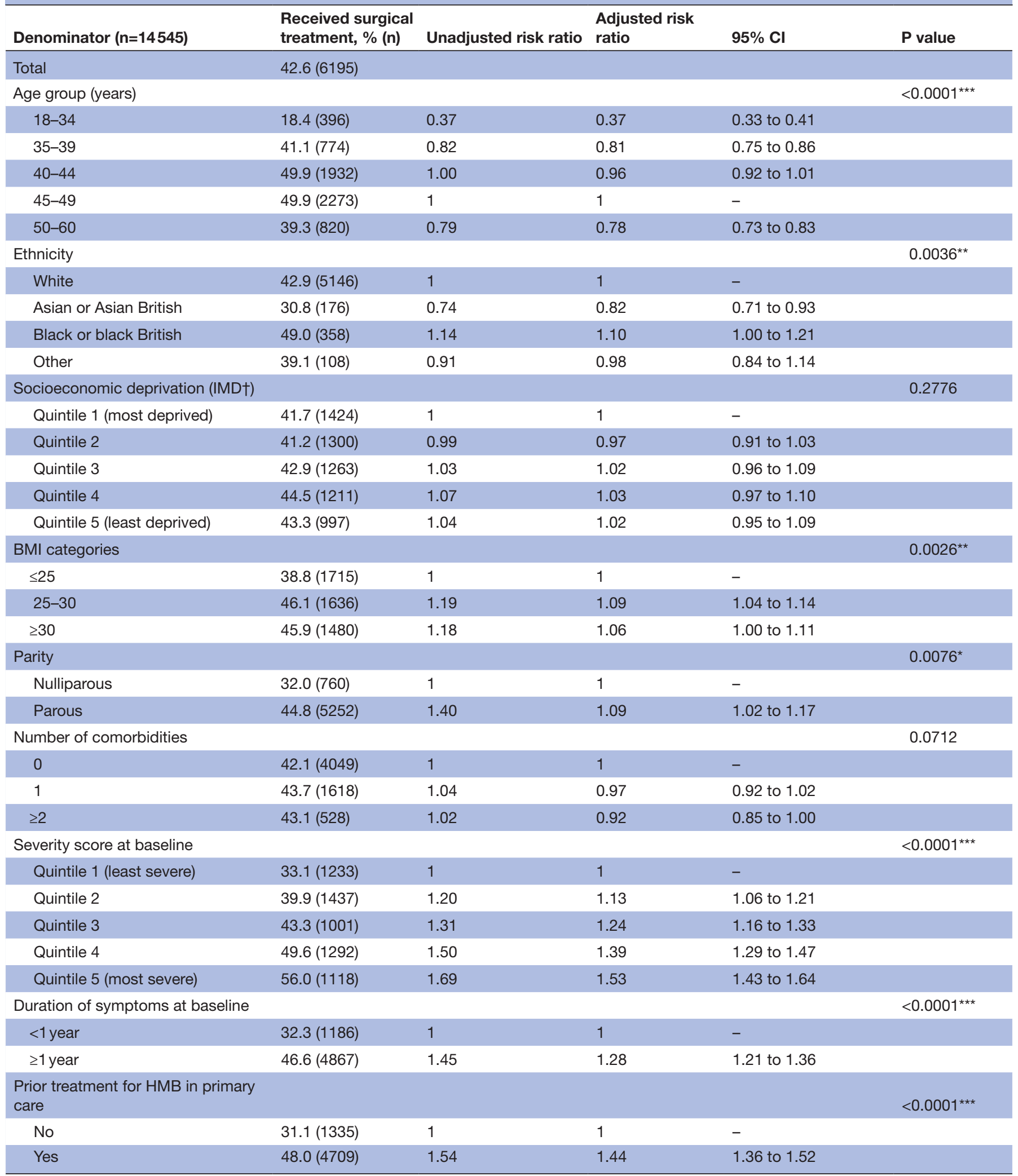

Multivariable model adjusted for age group, ethnicity, IMD, BMI, parity, number of comorbidities, baseline symptom severity and HMB treatment received in primary care. Categories compared using the Wald test.

${ }^{*} \mathrm{P}<0.05 ;{ }^{* *} \mathrm{P}<0.01 ;{ }^{* * *} \mathrm{P}<0.001$.

†Index of Multiple Deprivation, an area-level measure of relative socioeconomic deprivation.

$\mathrm{BMI}$, body mass index; HMB, heavy menstrual bleeding. 


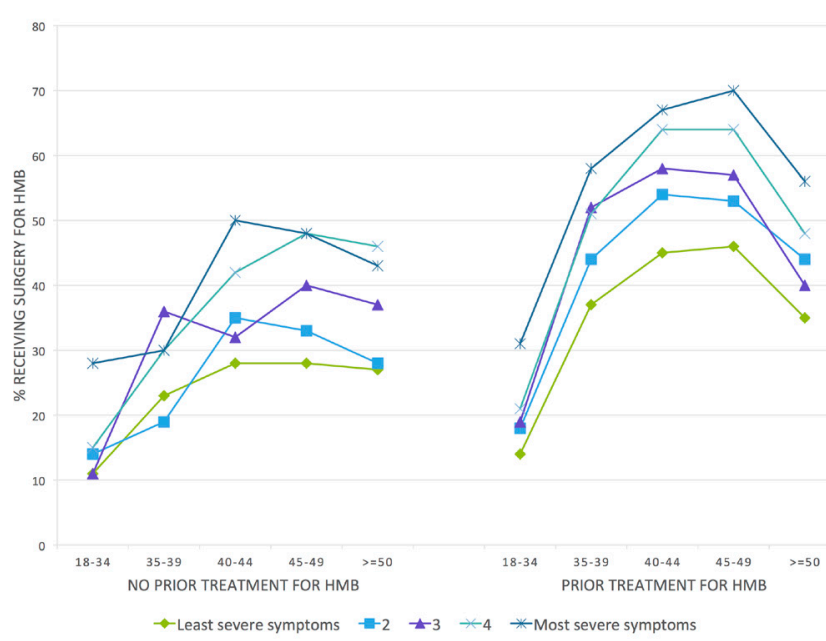

Figure 1 Receipt of surgery for heavy menstrual bleeding (HMB) based on prior treatment, age group and symptom severity quintile.

observed between both symptom severity, prior treatment in primary care and underlying condition and the likelihood of receiving hysterectomy.

Women with an underlying condition diagnosed were more likely to have received a hysterectomy than women with no obvious cause of their HMB diagnosed. Women were twice as likely to have had a hysterectomy (RR 2.1, $95 \%$ CI 1.9 to 2.4 ) if they had a diagnosis of uterine fibroids or polyps (without endometriosis) recorded, and four times more likely if they had endometriosis (with or without uterine fibroids or polyps) (RR 3.9, 95\% CI 3.4 to 4.5 , table 3 ). Of women who received a hysterectomy, $52.1 \%$ had a diagnosis of uterine fibroids or polyps (without endometriosis) recorded and $21.3 \%$ had endometriosis (with or without uterine fibroids or polyps). In contrast, more than half of women undergoing EA had no obvious cause of their HMB diagnosed (52.9\%; online supplementary appendix S4). There was no significant interaction between either ethnicity or BMI and underlying condition, although the power to detect a significant interaction in the complex relationship between ethnicity and HMB-related conditions would be small.

\section{DISCUSSION}

\section{Main findings}

Approximately $40 \%$ of women referred to secondary care for HMB in England and Wales received a form of surgical treatment in the first year following their initial outpatient clinic visit in secondary care. The rate of surgery was $50 \%$ higher among women who reported having received treatment in primary care prior to their first outpatient visit than among those who did not. In addition, more severe symptoms were also associated with higher rates of surgery, and with receiving hysterectomy rather than EA. Women with an Asian ethnic background had lower rates of surgery, while women with a black ethnic background had higher rates of surgery, after adjusting for symptom severity than women with a white ethnic background. Socioeconomic deprivation was not associated with the rate of surgery.

\section{Interpretation}

We previously reported that socioeconomic deprivation influences access to secondary care for $\mathrm{HMB}^{16}$ as for other conditions. ${ }^{26}$ However, our findings illustrate that once women reach secondary care services, their receipt of surgical treatment depends mainly on their symptom severity, and whether or not they have received treatment in primary care prior to their referral. Nearly one-third of women reported that they had no treatment for their HMB in primary care and the chance that these women had surgery within the first year after their referral was considerably lower than for women who had prior treatment in primary care. National guidelines for the management of HMB in the UK indicate that hormonal or non-hormonal medical therapy can be started in primary care. Our findings suggest that this may reduce the number of potentially inappropriate referrals to specialist services. ${ }^{5}$ However, immediate referral can be appropriate for women seeking further diagnostic tests and reassurance, even without medical treatment. ${ }^{6}$ 27-29 In addition, some women may be referred immediately because they do not wish to take drug treatment, or it is anticipated that treatment available in primary care may fail to control their symptoms to an acceptable level. ${ }^{5}$

We also observed variation in surgery rates by ethnic background, after accounting for symptom severity. Compared with white women, women reporting Asian ethnicity had lower rates of surgery, and women reporting black ethnicity had higher rates of surgery. These differences may reflect inequitable use of surgical care, or may be attributable to variations according to ethnicity in the prevalence of HMB-related conditions (such as fibroids), cultural norms (eg, accepting heavy periods as normal) and patient preferences for treatment, which have been reported previously. ${ }^{30-32}$ We observed higher surgery rates among overweight and obese women, which may also be attributable to the prevalence of HMB-related conditions such as fibroids. ${ }^{33} 34$

Since 2004, more EA procedures than hysterectomies have been conducted in England. ${ }^{11} 13$ However, little was previously known about the determinants of hysterectomy compared with EA. We have shown that the choice of procedure is strongly linked to symptom severity and HMB-related conditions, with a higher proportion of those who had worse symptoms, and those who had an underlying condition (uterine fibroids, polyps or endometriosis) diagnosed receiving a hysterectomy. All women should have the opportunity to discuss the benefits and risks of both EA and hysterectomy, to help them make informed decisions about their treatment. ${ }^{5}$

Despite the existence of national guidelines for the management of HMB in the UK, developed by the National Institute for Health and Care Excellence and the Royal College of Obstetricians and Gynaecologists, 53035 only 
Table 3 Characteristics associated with receiving hysterectomy (compared with endometrial ablation) in the first year following an initial outpatient visit for HMB

\begin{tabular}{|c|c|c|c|c|c|}
\hline Denominator $(n=5920)$ & $\begin{array}{l}\text { Received } \\
\text { hysterectomy, \% (n) }\end{array}$ & $\begin{array}{l}\text { Unadjusted risk } \\
\text { ratio }\end{array}$ & $\begin{array}{l}\text { Adjusted risk } \\
\text { ratio }\end{array}$ & $95 \% \mathrm{Cl}$ & $P$ value \\
\hline Total & $27.1(1606)$ & & & & \\
\hline Age group (years) & & & & & 0.0713 \\
\hline $18-34$ & $17.4(62)$ & 0.58 & 0.79 & 0.61 to 1.03 & \\
\hline $35-39$ & 25.5 (181) & 0.83 & 0.84 & 0.71 to 0.99 & \\
\hline $40-44$ & 25.7 (478) & 0.88 & 0.91 & 0.82 to 1.01 & \\
\hline $45-49$ & 29.9 (652) & 1 & 1 & - & \\
\hline $50-60$ & 29.1 (233) & 0.97 & 0.88 & 0.77 to 1.01 & \\
\hline Ethnicity & & & & & 0.1184 \\
\hline White & $26.8(1350)$ & 1 & 1 & - & \\
\hline Asian or Asian British & $27.7(44)$ & 1.04 & 0.75 & 0.91 to 1.00 & \\
\hline Black or black British & $34.9(88)$ & 1.30 & 1.13 & 1.09 to 1.39 & \\
\hline Other & $32.6(30)$ & 1.20 & 0.88 & 0.62 to 1.26 & \\
\hline $\begin{array}{l}\text { Socioeconomic } \\
\text { deprivation (IMD†) }\end{array}$ & & & & & 0.3004 \\
\hline $\begin{array}{l}\text { Quintile } 1 \text { (most } \\
\text { deprived) }\end{array}$ & 28.2 (378) & 1 & 1 & - & \\
\hline Quintile 2 & $24.4(298)$ & 0.86 & 0.93 & 0.80 to 1.08 & \\
\hline Quintile 3 & 26.3 (319) & 0.93 & 0.97 & 0.84 to 1.11 & \\
\hline Quintile 4 & 29.4 (344) & 1.04 & 1.01 & 0.94 to 1.24 & \\
\hline $\begin{array}{l}\text { Quintile } 5 \text { (least } \\
\text { deprived) }\end{array}$ & $27.4(267)$ & 0.97 & 1.03 & 0.89 to 1.19 & \\
\hline BMI categories & & & & & $0.0450^{\star}$ \\
\hline$\leq 25$ & 24.7 (399) & 1 & 1 & - & \\
\hline $25-30$ & $29.7(465)$ & 1.20 & 1.15 & 1.03 to 1.29 & \\
\hline$\geq 30$ & $28.0(400)$ & 1.13 & 1.08 & 0.96 to 1.21 & \\
\hline Parity & & & & & 0.2340 \\
\hline Nulliparous & $25.4(165)$ & 1 & 1 & - & \\
\hline Parous & $27.4(1404)$ & 1.09 & 0.95 & 0.82 to 1.10 & \\
\hline Number of comorbidities & & & & & 0.3223 \\
\hline 0 & 27.0 (1039) & 1 & 1 & - & \\
\hline 1 & 26.5 (414) & 0.98 & 0.97 & 0.86 to 1.08 & \\
\hline$\geq 2$ & 29.9 (153) & 1.11 & 1.12 & 0.95 to 1.32 & \\
\hline $\begin{array}{l}\text { Severity score at baseline } \\
\text { (quintiles) }\end{array}$ & & & & & $<0.0001^{\star \star \star}$ \\
\hline Quintile 1 (least severe) & $22.0(251)$ & 1 & 1 & - & \\
\hline Quintile 2 & $26.0(362)$ & 1.18 & 1.17 & 1.00 to 1.37 & \\
\hline Quintile 3 & $28.2(271)$ & 1.28 & 1.26 & 1.07 to 1.49 & \\
\hline Quintile 4 & $26.3(326)$ & 1.20 & 1.23 & 1.05 to 1.43 & \\
\hline Quintile 5 (most severe) & $33.9(365)$ & 1.54 & 1.57 & 1.34 to 1.83 & \\
\hline $\begin{array}{l}\text { Duration of symptoms at } \\
\text { baseline }\end{array}$ & & & & & $0.0078^{\star \star}$ \\
\hline$<1$ year & $24.2(273)$ & 1 & 1 & - & \\
\hline$\geq 1$ year & 28.0 (1304) & 1.16 & 1.20 & 1.05 to 1.36 & \\
\hline $\begin{array}{l}\text { Prior treatment for } \mathrm{HMB} \text { in } \\
\text { primary care }\end{array}$ & & & & & $0.0005^{\star * *}$ \\
\hline
\end{tabular}


Table 3 Continued

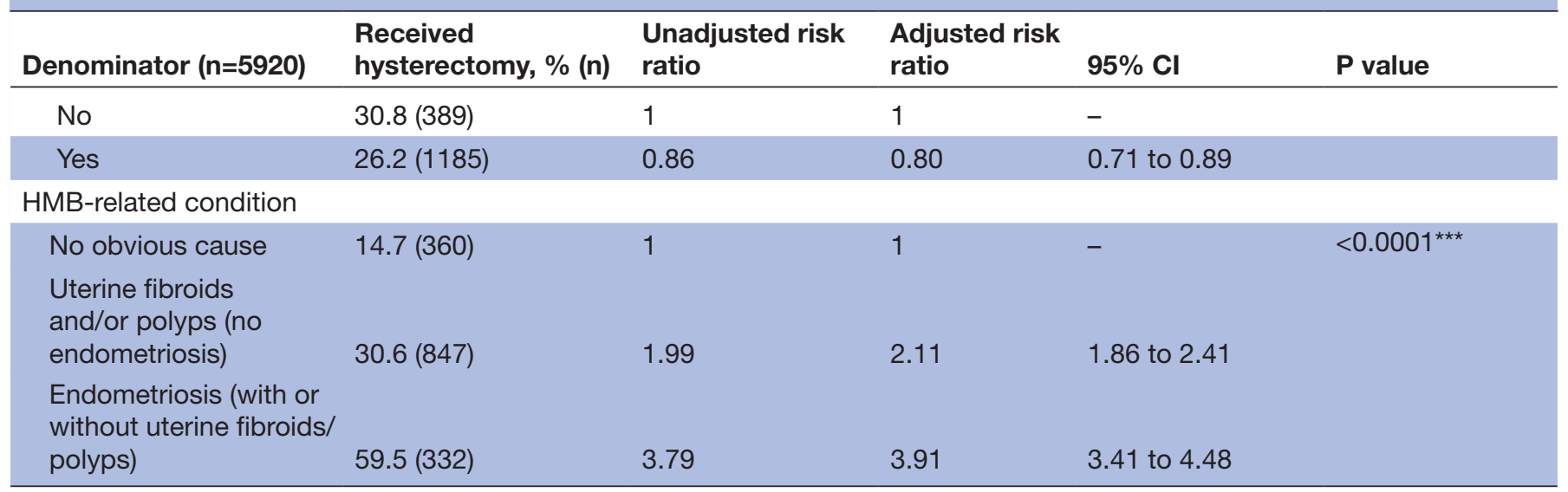

Multivariable model adjusted for age group, ethnicity, IMD, baseline BMI, parity and number of comorbidities, baseline symptom severity and $\mathrm{HMB}$ treatment received in primary care. A total of 699 women received both endometrial ablation (EA) and a hysterectomy in the year following their first outpatient visit. Here they are included in the EA group as this represents the first surgical treatment choice. Categories compared using the Wald test.

${ }^{*} \mathrm{P}<0.05 ;{ }^{* *} \mathrm{P}<0.01 ;{ }^{* * *} \mathrm{P}<0.001$.

†Index of Multiple Deprivation, an area-level measure of relative socioeconomic deprivation.

$\mathrm{BMI}$, body mass index; HMB, heavy menstrual bleeding.

a minority of hospitals in England and Wales reported local protocols on the management of women with HMB to the National HMB Audit. ${ }^{36}$ Local auditing of referral pathways could help ensure that referrals to secondary care without prior treatment in primary care reflect patient-centred care.

\section{Strengths and limitations}

A number of studies have reported treatment outcomes for women with $\mathrm{HMB}^{915}$ but our study is the first national study reporting on initial treatments for HMB immediately after referral to secondary care. It is also the first to examine the impact of sociodemographic factors and symptoms on the chance that women with HMB will receive surgical treatment. We used data collected by a national clinical audit in England and Wales, linked to administrative hospital data, which produced a large sample. We estimated that the National HMB Audit recruited approximately a third of all eligible women. While the recruitment rate was not as high as desired, the characteristics of those recruited were broadly representative of the UK population in terms of ethnicity and age $^{37} 38$ and the sample size was large. Information on women's fertility intentions was not available, so we could not explore whether this influenced observed associations between age and ethnicity and receiving surgery.

\section{CONCLUSIONS}

Once women reach secondary care services, the chance that they will have surgical treatment within a year is strongly linked to their symptom severity and age and also, although less strongly, to their parity, BMI and ethnic background. Having received treatment in primary care before referral also increases the likelihood of surgery after referral. Our finding that a third of women were referred without prior treatment in primary care may raise questions about whether these referrals were appropriate. However, some women may benefit from referral for advice and further assessment, or may seek immediate surgical treatment. We recommend that referral pathways between primary and secondary care should be locally audited to ensure that the care that women with HMB receive addresses their individual needs and preferences.

\section{Author affiliations}

${ }^{1}$ Department of Health Services Research and Policy, London School of Hygiene and Tropical Medicine, London, UK

${ }^{2}$ Lindsay Stewart Centre for Audit and Clinical Informatics, Royal College of Obstetricians and Gynaecologists, London, UK

${ }^{3}$ Institute of Epidemiology and Health, University College London, London, UK

${ }^{4}$ Royal College of General Practitioners, London, UK

Acknowledgements We thank all the NHS providers and patients who participated in the National HMB Audit. We also thank the Healthcare Quality Improvement Partnership, the Health and Social Care Information Centre and the Royal College of Surgeons of England for providing the authors with the data required for this study.

Contributors TM and JvdM derived the research question. AK, IGU, DAC and LBM supported data collection directly and JS, TM and JvdM advised. RSG performed the analyses and wrote the manuscript. All authors contributed to and approved the manuscript.

Funding The National Heavy Menstrual Bleeding (HMB) Audit was commissioned by the Healthcare Quality Improvement Partnership (HQIP) as part of the National Clinical Audit and Patient Outcomes Programme (NCAPOP) (contract number HQIP NCA 004). HQIP is led by a consortium of the Academy of Medical Royal Colleges, the Royal College of Nursing and National Voices. Its aim is to promote quality improvement in patient outcomes, and in particular, to increase the impact that clinical audit, outcome review programmes and registries have on healthcare quality in England and Wales. HQIP holds the contract to commission, manage and develop the NCAPOP, comprising around 40 projects covering care provided to people with a wide range of medical, surgical and mental health conditions. The programme is funded by the NHS England, the Welsh Government, and with some individual projects, other devolved administrations and crown dependencies (www. hqip.org.uk/national-programmes). 
Disclaimer This publication is based on data collected by or on behalf of the Healthcare Quality Improvement Partnership, who have no responsibility or liability for the accuracy, currency, reliability and/or correctness of this publication.

Competing interests None declared.

Patient consent for publication Not required.

Ethics approval The study is exempt from UK National Research Ethics Service (NRES) approval because it involved the analysis of an existing data set of anonymised data for service evaluation. Based on the Health Research Authority's guidance, audits are regulated as standard clinical practice outside of the Research Ethics Service. Approvals for the use of anonymised HES data were obtained as part of the standard HES data access process.

Provenance and peer review Not commissioned; externally peer reviewed.

Data sharing statement The National HMB Audit was identified as an eligible audit in the Prime Minister's transparency agenda in 2011. The provider-level data from the second and third annual reports are now available. For more information, please visit the National HMB Audit data transparency page (https://goo.gl/pHwFjv). The full HMB Audit data are available on request from the Healthcare Quality Improvement Partnership.

Open access This is an open access article distributed in accordance with the Creative Commons Attribution Non Commercial (CC BY-NC 4.0) license, which permits others to distribute, remix, adapt, build upon this work non-commercially, and license their derivative works on different terms, provided the original work is properly cited, appropriate credit is given, any changes made indicated, and the use is non-commercial. See: http://creativecommons.org/licenses/by-nc/4.0/.

\section{REFERENCES}

1. Marjoribanks J, Lethaby A, Farquhar C. Surgery versus medical therapy for heavy menstrual bleeding. Cochrane Database Syst Rev 2016:CD003855

2. Royal College of Obstetricians and Gynaecologists, London School of Hygiene \& Tropical Medicine, Ipsos MORI. National Heavy Menstrual Bleeding Audit: Third Annual Report: RCOG Press, 2013.

3. Coulter A, Bradlow J, Agass M, et al. Outcomes of referrals to gynaecology outpatient clinics for menstrual problems: an audit of general practice records. Br J Obstet Gynaecol 1991;98:789-96.

4. Royal College of Obstetricians and Gynaecologists, London School of Hygiene \& Tropical Medicine, Ipsos MORI. National Heavy Menstrual Bleeding Audit: First Annual Report: RCOG Press, 2011.

5. National Institute for Health and Care Excellence (NICE). Heavy Menstrual Bleeding: NICE quality standard 47NICE, 2013.

6. NICE. Heavy Menstrual Bleeding. 44, 2007.

7. McPherson K, Metcalfe MA, Herbert A, et al. Severe complications of hysterectomy: the VALUE study. BJOG 2004;111:688-94.

8. Bansi-Matharu L, Gurol-Urganci I, Mahmood TA, et al. Rates of subsequent surgery following endometrial ablation among English women with menorrhagia: population-based cohort study. BJOG 2013;120:1500-7.

9. Bhattacharya S, Middleton LJ, Tsourapas A, et al. Hysterectomy, endometrial ablation and Mirena ${ }^{\circledR}$ for heavy menstrual bleeding: a systematic review of clinical effectiveness and cost-effectiveness analysis. Health Technol Assess 2011;15:iii-xvi, 1-252.

10. Lethaby A, Penninx J, Hickey M, et al. Endometrial resection and ablation techniques for heavy menstrual bleeding. Cochrane Database Syst Rev 2013;80.

11. Reid PC. Endometrial ablation in England--coming of age? An examination of hospital episode statistics 1989/1990 to 2004/2005. Eur J Obstet Gynecol Reprod Biol 2007;135:191-4.

12. Cromwell DA, Mahmood TA, Templeton A, et al. Surgery for menorrhagia within English regions: variation in rates of endometrial ablation and hysterectomy. BJOG 2009;116:1373-9.

13. Royal College of Obstetricians and Gynaecologists, London School of Hygiene \& Tropical Medicine, Ipsos MORI. National Heavy Menstrual Bleeding Audit: Final Report: RCOG Press, 2014.
14. Grant $\mathrm{C}$, Gallier L, Fahey $\mathrm{T}$, et al. Management of menorrhagia in primary care-impact on referral and hysterectomy: data from the somerset morbidity project. J Epidemiol Community Health 2000;54:709-13.

15. Warner P, Critchley HO, Lumsden MA, et al. Referral for menstrual problems: cross sectional survey of symptoms, reasons for referral, and management. BMJ 2001;323:24-8.

16. Kiran A, Geary RS, Gurol-Urganci I, et al. Sociodemographic differences in symptom severity and duration among women referred to secondary care for menorrhagia in england and wales: a cohort study from the national heavy menstrual bleeding audit. BMJ Open 2018;8:e018444.

17. Royal College of Obstetricians and Gynaecologists, London School of Hygiene \& Tropical Medicine, Ipsos MORI. National Heavy Menstrual Bleeding Audit: Second Annual Report: RCOG Press, 2012.

18. HSCIC. Appendix 1office of population, censuses and surveys's classification of surgical operations and procedures, codes and descriptions of procedures of common surgical groups. http:// systems.hscic.gov.uk/data/clinicalcoding/codingstandards/opcs4.

19. World Health Organization. International Classification of Diseases. 10 edn. http://apps.who.int/classifications/icd10/browse/2016/en.

20. World Health Organisation. BMI Classification. 2016;10 http://apps. who.int/bmi/index.jsp? introPage=intro_3.html.

21. Spies JB, Coyne K, Guaou Guaou N, et al. The UFS-QOL, a new disease-specific symptom and health-related quality of life questionnaire for leiomyomata. Obstet Gynecol 2002;99:290-300.

22. Knol MJ, Le Cessie S, Algra A, et al. Overestimation of risk ratios by odds ratios in trials and cohort studies: alternatives to logistic regression. CMAJ 2012;184:895-9.

23. Royston P. Multiple imputation of missing values. The Stata Journal 2005;5:527-36.

24. Rubin D. Multiple imputation for non-response in surveys. New York: John Wiley \& Sons, 1987.

25. Office for National Statistics. Ethnicity and National Identity in England and Wales: 2011. $2011 \mathrm{https} / / / \mathrm{www} .0 n s . g o v . u k / p e o p l e p o$ pulationandcommunity/culturalidentity/ethnicity/articles/ethnicityand nationalidentityinenglandandwales/2012-12-11.

26. Lyratzopoulos G, Barbiere JM, Greenberg DC, et al. Population based time trends and socioeconomic variation in use of radiotherapy and radical surgery for prostate cancer in a UK region: continuous survey. BMJ 2010;340:c1928.

27. Royal College of Obstetricians and Gynaecologists. The initial management of menorrhagia, in Evidence-based clinical guidelines. London: RCOG, 1998.

28. Royal College of Obstetricians and Gynaecologists. The Management of Menorrhagia in Secondary Care, in Evidence-based clinical guidelines. London: RCOG, 1999.

29. Coulter A, Long A, Kelland J, et al. Managing menorrhagia. Qual Health Care 1995;4:218-26.

30. National Institute for Health and Care Excellence (NICE). NICE support for commissioning for heavy menstrual bleeding, 2013.

31. Chapple A. Iron deficiency anaemia in women of South Asian descent: a qualitative study. Ethn Health 1998;3:199-212.

32. Vuorma S, Teperi J, Hurskainen R, et al. Correlates of women's preferences for treatment of heavy menstrual bleeding. Patient Educ Couns 2003;49:125-32.

33. Ratner $\mathrm{H}$. Risk factors for uterine fibroids: reduced risk associated with oral contraceptives. BMJ 1986;293:1027.

34. Wise LA, Laughlin-Tommaso SK. Epidemiology of uterine fibroids: from menarche to menopause. Clin Obstet Gynecol 2016;59:2-24.

35. Royal College of Obstetricians and Gynaecologists. Standards for gynaecology. Report of a Working Party 2008.

36. Cox SM, Cromwell D, Mahmood T, et al. The delivery of heavy menstrual bleeding services in England and Wales after publication of national guidelines: a survey of hospitals. BMC Health Serv Res 2013;13:491.

37. Office for National Statistics. Ethnicity. 2002;2002.

38. Office for National Statistics. Ethnicity and national identity in England and Wales 2011. 2012. 